\title{
Emergency repair of traumatic aortic rupture: Endovascular versus conventional open repair
}

\author{
Enoch Akowuah, MD, MRCS, ${ }^{a}$ Andreas Baumbach, FRCP, FESC, ${ }^{\mathrm{b}}$ Peter Wilde, FRCR, MRCP, \\ Gianni Angelini, MD, MCh, FRCS, ${ }^{a}$ and Alan J. Bryan, DM, FRCS (CTh) ${ }^{\mathrm{a}}$
}

From the Departments of Cardiothoracic Surgery ${ }^{\mathrm{a}}$ and Cardiology, ${ }^{\mathrm{b}}$ Bristol Heart Institute at the Bristol Royal Infirmary, Bristol, United Kingdom.

Andreas Baumbach, FRCP, FESC, reports consulting fees from Abbott Vascular and Boston Scientific and grant support from Boston Scientific.

Received for publication March 26, 2007; revisions received June 5, 2007; accepted for publication June 15, 2007.

Address for reprints: Alan J. Bryan, DM, FRCS (CTh), Consultant Cardiac Surgeon, Bristol Heart Institute, Bristol Royal Infirmary, Upper Maudlin St, Bristol BS2 8HN, United Kingdom (E-mail: Alan.Bryan@ ubht.swest.nhs.uk).

J Thorac Cardiovasc Surg 2007;134:897-901 0022-5223/\$32.00

Copyright $(9) 2007$ by The American Association for Thoracic Surgery

doi:10.1016/j.jtcvs.2007.06.019
Objective: Our objective was to compare early results of endovascular stenting for traumatic aortic rupture with conventional open repair.

Methods: We conducted a retrospective review of consecutive cases of traumatic aortic rupture in a single institution from July 2000 to July 2006.

Results: Fifteen cases were identified. The mean injury severity score was $43 \pm 10$. Fourteen patients had the procedure within 24 hours of admission to the hospital. Seven patients underwent endovascular stenting and 8 underwent open repair. For endovascular stenting, there were no failed procedures, no periprocedural complications, and no periprocedural deaths. In 6 patients, there was no evidence of endoleak, stent migration, or late pseudoaneurysm formation. One patient required a second stent 2 years later to treat a stenosis in the original stent. For open repair, cardiopulmonary bypass was used in 7 of the 8 patients. Lower limb paraplegia developed postoperatively in 1 patient and another patient died of head injuries. There was a significant reduction in the mean duration of the procedure $(2.2 \pm 0.90$ vs $5 \pm 3.2$ hours; $P=0.04)$, the mean intraoperative blood loss (311 \pm 20 vs $953 \pm$ $20 \mathrm{~mL} ; P=.02$ ), the mean number of units of blood and blood products used $(0.43 \pm 1.1$ vs $3 \pm 3$ units; $P=.026)$, and the mean dose of heparin required $(5000 \pm 1700$ vs $24,000 \pm 7500 \mathrm{IU} ; P=.001)$ in the endovascular stenting group. There was no difference in duration of ventilation, intensive treatment unit, or hospital stay.

Conclusions: Endovascular stenting is technically feasible and applicable to a range of cardiac patients. It takes less time than open repair, requires less heparin and blood products, and therefore simplifies management of other injuries. In hemodynamically stable patients, endovascular stenting is the treatment of choice for traumatic aortic rupture.

$\mathrm{T}$ Traumatic aortic rupture (TAR) after blunt trauma carries a very high mortality rate. The initial reports suggested a subsequent mortality of over $80 \%$ at the scene of the injury and a mortality rate increasing by $1 \%$ per hour. ${ }^{1,2}$

In the few patients who survived to undergo treatment, the original techniques that were used involved the use of simple aortic suture or the use of aortic clamps without extracorporeal support, the so-called clamp-and-sew technique. These techniques were associated with relatively high rates of postoperative paraplegia, $20 \%$ in one meta-analysis. ${ }^{3}$ Over recent decades it has been recognized that the use of extracorporeal support, usually left heart bypass, results in a reduction in paraplegia rates. ${ }^{3}$ Despite this, paraplegia rates are still substantial, $2.3 \%$ to $12 \%$, and morbidity and mortality remain high, up to $18 \%$ after conventional open surgery. ${ }^{3,4}$ Moreover, these patients typically have other severe injuries, and the use of extracorporeal circulation, particularly the use of systemic heparinization, complicates the management of those injuries. 

Abbreviations and Acronyms
$\mathrm{CT}=$ computed tomography
$\mathrm{ER}=$ endovascular repair
$\mathrm{OR}=$ open repair
$\mathrm{TAR}=$ traumatic aortic rupture

More recently, the use of endovascular stenting of the descending thoracic aorta to treat a variety of pathologic conditions has become well established. Several reports and registry data have shown that these procedures are generally technically feasible, and midterm results have demonstrated both efficacy and safety. ${ }^{5-7}$ These techniques are readily applicable to the treatment of TAR and there have been several reports of the use of endoluminal stenting in this setting. ${ }^{7-9}$ However, in most of these reports, stenting has been performed several days after the injury in hemodynamically stable patients after associated injuries had been treated.

A program of aortic stenting commenced in our unit in 2003. Patients admitted with TAR were treated on an emergency basis (within 24 hours) in all cases. In this study we evaluate early results of emergency endovascular repair (ER) of TAR in a single unit during the past 6 years.

\section{Patients and Methods}

From January 2000 to July 2006, all patients treated for TAR in our institution were identified and placed on a prospective database. A retrospective review of all case notes and operation notes was performed.

\section{Diagnosis}

TAR was diagnosed in patients who had trauma involving the aorta and who on contrast-enhanced computed tomographic (CT) scanning demonstrated traumatic injury to the aorta. All patients sustained the typical pattern of injury at the aortic isthmus. The cohort was divided into 2 groups, endovascular repair (ER) and open repair $(\mathrm{OR})$.

\section{Surgical Treatment}

A left posterolateral thoracotomy approach with an incision in the fourth intercostal space was used in all cases. When possible, single lung ventilation excluding the left lung was used. All patients received intravenous heparin in a dose of $300 \mathrm{IU} / \mathrm{kg}$ of body weight.

Extracorporeal circulatory support was used for the majority of cases. In most cases left atrial and femoral artery or distal aortic bypass were used. In some cases cardiopulmonary bypass with femoral artery and femoral vein cannulation was used.

After extracorporeal circulation was established, vascular clamps were applied between the left common carotid artery and the left subclavian artery proximally and to the distal thoracic aorta beyond the site of injury distally. The aorta was repaired with a gel-impregnated woven Dacron prosthesis used as an interposition graft in all cases.

\section{Endovascular Treatment}

ER was performed with the patient under general anesthesia in the cardiac catheterization suite. A cardiac surgeon and an interventional cardiovascular radiologist/cardiologist were present for all cases.

After the administration of a single dose of 5000 IU of intravenous heparin, the common femoral artery was dissected and an 8- to $10-\mathrm{mm}$ Dacron graft was sutured to the artery to provide access to the thoracic aorta. An angiography catheter was then passed into the ascending aorta and an aortogram of the entire aorta performed to establish the diagnosis.

The Talent endoprosthesis (Medtronic, Inc, St Paul, Minn) was used. The diameter of the endoprosthesis required was measured from the CT scan. The stent was slightly oversized to ensure a good seal. The stent was then deployed in the descending aorta under fluoroscopic guidance. At the end of the procedure, an aortogram was performed to ensure satisfactory positioning of the stent and to confirm the absence of a leak. After removal of the delivery system, the Dacron graft was tied off and the femoral incision site closed with polyglactin 910 sutures (Vicryl; Ethicon, Inc, Somerville, NJ).

\section{Statistical Analysis}

Categorical data are presented as frequency (percentage) and continuous data as mean \pm standard deviation or median with interquartile ranges. Comparison of continuous data was by the Student $t$ test for normally distributed data and Mann-Whitney test for nonnormally distributed data. Comparison of categorical data was by $\chi^{2}$ test for normally distributed data and Fisher exact test for nonnormally distributed data.

\section{Results}

A total of 15 cases of TAR were identified during the study period. The mechanism of injury was road traffic accident in 13 cases (motorcycle 7 cases, motor vehicle in 5 cases) and falls from a height in 2 cases. The mean age was $30 \pm 12$ years and $75 \%$ of the patients were male. The mean injury severity score was $43 \pm 0$. Tables 1 and 2 list the patients and their associated injuries.

CT scan established the diagnosis in 13 patients. In 2 patients the CT scan was suggestive but an aortogram had to be performed to confirm the diagnosis. In all patients the site of aortic injury was at the isthmus. Fourteen patients had the procedure within 24 hours of admission to the hospital. One patient had an OR 72 hours after admission.

Seven patients underwent ER compared with 8 who underwent OR. Figure 1 demonstrates the transition from OR to ER, which occurred in 2004. Of the last 8 patients in the series, 7 were treated with ER.

There was no difference in the ER and OR groups with respect to age $(32 \pm 15$ vs $28 \pm 9$ years; $P=.4)$ or the mean injury severity score $(42 \pm 5$ vs $44 \pm 13 ; P=.3)$, respectively.

For ER, there were no technical or operative failures. All patients received a single stent, mean length $25 \pm 1 \mathrm{~mm}$. There was no conversion to an open approach. No patient 
TABLE 1. Demographic features and details of associated injuries of the cohort (OR group)

\begin{tabular}{|c|c|c|c|c|c|c|}
\hline $\begin{array}{l}\text { Patient } \\
\text { no. }\end{array}$ & Age (y) & Sex & Year & Mechanism of injury & $\begin{array}{c}\text { Time to } \\
\text { repair }\end{array}$ & Associated injuries \\
\hline 1 & 25 & M & 2004 & RTA (motor vehicle) & $72 \mathrm{~h}$ & Fractured pelvis; cerebral contusion; pulmonary contusion \\
\hline 2 & 18 & $\mathrm{~F}$ & 2002 & RTA (motorcycle) & $<24 \mathrm{~h}$ & $\begin{array}{l}\text { Fractured basal skull, pelvis, femur, tibia, humerus, C1, C2 vertebrae; } \\
\text { splenic laceration; pneumothorax; lung contusion; cerebral } \\
\text { contusion; tear of small bowel mesentery }\end{array}$ \\
\hline 3 & 29 & M & 2001 & RTA (motorcycle) & $<24 \mathrm{~h}$ & Fractured femur, T2 to T7 vertebrae, radius, ulna; cerebral contusion \\
\hline 4 & 17 & $\mathrm{M}$ & 2002 & RTA (motorcycle) & $<24 \mathrm{~h}$ & Fractured frontal sinus; splenic contusion \\
\hline 5 & 28 & M & 2002 & RTA (motor vehicle) & $<24 \mathrm{~h}$ & Fractured pelvis, ribs; lung contusion \\
\hline 6 & 46 & $\mathrm{~F}$ & 2004 & Jump from bridge & $<24 \mathrm{~h}$ & Fractured mandible, pelvis, tibia, femur \\
\hline 7 & 29 & $\mathrm{M}$ & 2004 & RTA (motor vehicle) & $<24 \mathrm{~h}$ & Fractured humerus \\
\hline 8 & 33 & M & 2001 & RTA (motorcycle) & $<24 \mathrm{~h}$ & Fractured pelvis, radius, ulna, tibia, fibula; scrotal injury \\
\hline
\end{tabular}

$O R$, Open repair; $R T A$, road traffic accident.

had a periprocedural complication. There were no instances of renal failure or perioperative death. All patients had a repeat CT scan before discharge and yearly afterward. In 6 patients, the durability ER was confirmed, with no evidence of endoleak, stent migration, or late pseudoaneurysm formation.

One patient had an initially excellent result, but left arm claudication subsequently developed, presumably owing to occlusion of the origin of the left subclavian artery. The same patient required a second uncovered stent, 2 years after the initial procedure, to treat symptoms of acute coarctation resulting from a stenosis at the distal end of the original stent.

For OR, extracorporal circulatory support was used in 7 of the 8 patients. One patient had a clamp-and-sew procedure because of sudden hemorrhage. For patients requiring cardiopulmonary bypass, the mean duration of bypass was $123 \pm 67$ minutes and of aortic crossclamping, $41 \pm 24$ minutes. There was 1 case of paraplegia in a patient who had interposition graft insertion without extracorporeal circulatory support.

There was 1 death. In this patient technical difficulties with proximal vascular control necessitated the use of circulatory arrest. The patient died of massive cerebral injury 2 weeks after the operation.
Compared with the OR group, there was a significant reduction in the mean duration of the procedure $(2.2 \pm 0.90$ vs $5 \pm 3.2$ hours; $P=.04$ ) in the ER group. The mean intraoperative blood loss and the mean number of units of blood and blood products used were also significantly reduced in the ER group compared with the OR group (311 \pm 20 vs $953 \pm 20 \mathrm{~mL} ; P=.02$, and $0.43 \pm 1.1$ vs $3 \pm 3$ units of blood products; $P=.026$, respectively). Finally, the mean dose of heparin required for the procedure was also significantly less in the ER group (5000 \pm 1700 vs $24,000 \pm$ $7500 \mathrm{IU} ; P=.001)$. There was no difference in duration of ventilatory support $(1.7 \pm 0.7$ vs $3 \pm 3$ days; $P=.08)$, the length of stay in the intensive care unit $(2.8 \pm 0.9$ vs $4.2 \pm 4$ days; $P=.1)$, or duration of hospital stay $(10 \pm 9$ vs $17 \pm 14$ days) for the ER and OR groups, respectively.

\section{Discussion}

Surgery of TAR is uncommon in the United Kingdom. In 2003, the National Adult Cardiac Surgical Database reported only 21 cases in the whole of Great Britain and Ireland. ${ }^{10}$ Patients undergoing surgery often have other similarly severe associated injuries, further complicating the procedure. In a meta-analysis of nearly 1800 cases, the mortality of patients who reached the hospital alive was $32 \%$. Paraplegia developed postoperatively in $10 \%{ }^{3}$ More

TABLE 2. Demographic features and details of associated injuries of the cohort (ER Group)

\begin{tabular}{cccclll}
\hline $\begin{array}{l}\text { Patient } \\
\text { no. }\end{array}$ & Age (y) & Sex & Year & Mechanism of injury & $\begin{array}{c}\text { Time to } \\
\text { repair }\end{array}$ & \multicolumn{1}{c}{ Associated injuries } \\
\hline 1 & 28 & F & 2004 & RTA (motor vehicle) & $<24 \mathrm{~h}$ & Fractured spinal process, humerus, pelvis; dislocated hip; liver hematoma \\
2 & 19 & M & 2006 & RTA (motorcycle) & $<24 \mathrm{~h}$ & Fractured femur; splenic contusion \\
3 & 34 & M & 2005 & RTA (motorcycle) & $<24 \mathrm{~h}$ & Fractured pelvis \\
4 & 65 & F & 2006 & Jump from bridge & $<24 \mathrm{~h}$ & Fractured pelvic \\
5 & 34 & M & 2006 & RTA (motor vehicle) & $<24 \mathrm{~h}$ & Fractured sacrum; ruptured spleen; ruptured diaphragm \\
6 & 27 & M & 2004 & RTA (motor vehicle) & $<24 \mathrm{~h}$ & Fractured tibia \\
7 & 23 & M & 2006 & RTA (motorcycle) & $<24 \mathrm{~h}$ & Fractured T8 and T9 vertebrae; flailed chest; lung contusion
\end{tabular}

$E R$, Endovascular repair; RTA, road traffic accident. 


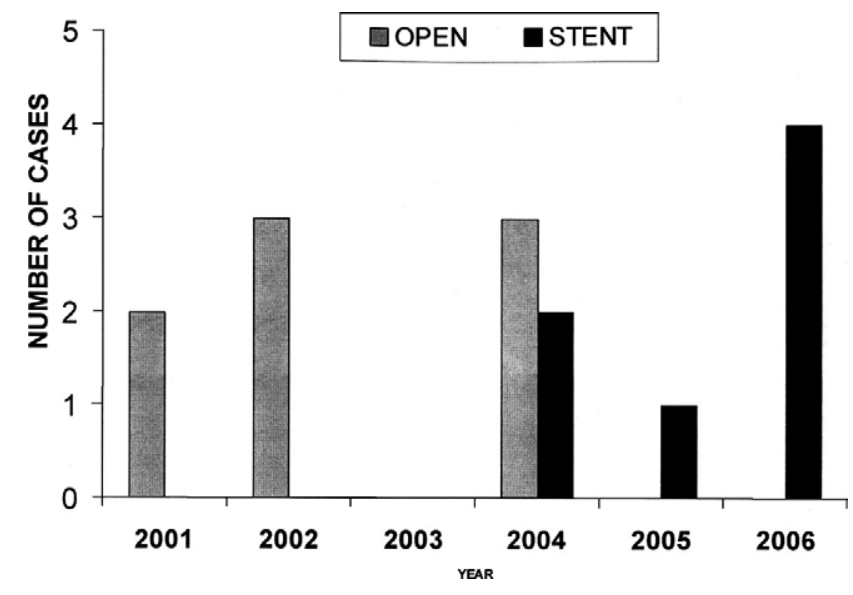

Figure 1. Transition from open to endovascular repair over the period of the study.

recent data from the National Adult Cardiac Surgical Database of The Society of Cardiothoracic Surgeons of Great Britain and Ireland in 2003 report an operative mortality of $28.6 \% .^{10}$ As with many cardiac surgical conditions, the outcomes recorded in registries are significantly worse than those seen in case series from centers undertaking a large volume of such cases. Familiarity allows operative and perfusion techniques to evolve and, in particular, repair to be performed with only a short period of aortic clamping.

One approach proposed to ameliorate the overall risk is to delay aortic surgery until the patient is in hemodynamically stable condition and other major injuries are treated. Improved operative results have been reported with this approach. ${ }^{11}$ Nevertheless, because of the danger of a second fatal rupture resulting from the delay to definitive treatment, estimated to occur in $5 \%$ of patients, this remains a controversial approach. ${ }^{3}$ Moreover, maintenance of relative hypotension can be difficult, particularly in cases of severe cerebral injury and raised intracranial pressure. ${ }^{12}$ In our view, the treatment of choice for this condition is urgent endovascular stenting. With the appropriate prioritization of other injuries, there seems little indication to delay the aortic intervention unnecessarily.

A program of thoracic aortic stenting, mainly for aneurysmal disease, was developed in our unit in 2003. This technique was identified as readily applicable to the treatment of TAR. In this study, equivalent results have been demonstrated with both ER and OR techniques. Of note is that, in the acute setting, the procedure is technically feasible and equally applicable to a range of patients. There were no conversions to conventional open surgery in our series. The main advantages are that it can be performed expeditiously and, because much lower doses of heparin are required, the management of other severe injuries becomes less complex. Finally, there is a significant decrease in the use of blood and blood products. As expected, duration of ventilatory support, intensive care unit stay, and hospital stay are predominantly determined by the extent of other injuries, particularly intra-abdominal, orthopedic, and cerebral.

Several groups have reported their experience with ER of TAR. ${ }^{13-17}$ The largest series with the longest follow-up was recently reported by Marcheix and associates. ${ }^{18}$ They followed up 33 patients who had ER over a 10-year period for a mean duration of 2.5 years. In keeping with previous studies, they demonstrated technical feasibility and low periprocedural complication rates. Again, unlike our series, only 4 of the 33 (12\%) patients were treated within 24 hours of their injury. Actuarial freedom from complications at 1 and 5 years was $96 \%$ and $85 \%$, respectively.

There have been few articles comparing conventional OR and ER for TAR. Such comparisons are hampered by the small number of cases, owing to the relative rarity of this condition, and by the fact that they are all retrospective case series. ${ }^{19,20}$ The largest comparative study by Amabile and colleagues ${ }^{21}$ compared 20 patients, 11 undergoing OR and 9 undergoing ER. In accordance with our experience, they reported early outcome with ER to be at least as good as that with OR. Unlike our study, the mean delay from injury to surgery in the endovascular group was 17 days.

The main limitation of this study is that the cohort is small and heterogeneous and the study is retrospective. Also, longterm durability of ER of traumatic aortic transection remains unknown. Ideally, yearly CT scans are required to ensure stability of the stent. However, given the absence of underlying aortic disease and the age of the patient population, this is highly unlikely to be of major concern.

Nevertheless, we conclude that ER is technically feasible and applicable to a range of patients early after TAR. It takes less time, requires less heparin and blood products, and therefore simplifies management of other injuries.

\section{References}

1. Parmley LF, Manion WC, Mattingly TW. Nonpenetrating traumatic injury of the heart. Circulation. 1958;18:371-96.

2. Cowley RA, Turney SZ, Hankins JR, Rodriguez A, Attar S, Shankar BS. Rupture of thoracic aorta caused by blunt trauma. A fifteen-year experience. J Thorac Cardiovasc Surg. 1990;100:652-60.

3. von Oppell UO, Dunne TT, De Groot MK, Zilla P. Traumatic aortic rupture: twenty-year metaanalysis of mortality and risk of paraplegia. Ann Thorac Surg. 1994;58:585-93.

4. Nzewi O, Slight RD, Zamvar V. Management of blunt thoracic aortic injury. Eur J Vasc Endovasc Surg. 2006;31:18-27. Epub 2005 Oct 14. Review.

5. Fattori R, Nienaber CA, Rousseau H, Beregi JP, Heijmen R, Grabenwoger M, et al, for theTalent Thoracic Retrospective Registry. Results of endovascular repair of the thoracic aorta with the Talent Thoracic stent graft: the Talent Thoracic Retrospective Registry. J Thorac Cardiovasc Surg. 2006;132:332-9.

6. Velu RB, Halak M, Muhlmann M, Baker S. Stent grafts for thoracic aortic pathology: single-center experience in Western Australia. Vascular. 2005;13:343-9.

7. Scheinert D, Krankenberg H, Schmidt A, Gummert JF, Nitzsche S, Scheinert S, et al. Endoluminal stent-graft placement for acute rupture of the descending thoracic aorta. Eur Heart J. 2004;25:694-700. 
8. Peterson BG, Matsumura JS, Morasch MD, West MA, Eskandari MK. Percutaneous endovascular repair of blunt thoracic aortic transection. J Trauma. 2005;59:1062-5.

9. Wellons ED, Milner R, Solis M, Levitt A, Rosenthal D. Stent-graft repair of traumatic thoracic aortic disruptions. J Vasc Surg. 2004;40: 1095-100.

10. The Society of Cardiothoracic Surgeons of Great Britain and Ireland. Fifth National Adult Cardiac Surgical Database Report 2003. Henley on Thames: Dendrite Clinical Systems; 2004.

11. Reed AB, Thompson JK, Crafton CJ, Delvecchio C, Giglia JS. Timing of endovascular repair of blunt traumatic thoracic aortic transections. J Vasc Surg. 2006;43:684-8.

12. Pate JW, Gavant ML, Weiman DS, Fabian TC. Traumatic rupture of the aortic isthmus: program of selective management. World J Surg. 1999;23:59-63.

13. Schoder M, Cartes-Zumelzu F, Grabenwoger M, Cejna M, Funovics M, Krenn CG, et al. Elective endovascular stent-graft repair of atherosclerotic thoracic aortic aneurysms: clinical results and midterm follow-up. AJR Am J Roentgenol. 2003;180:709-15.

14. Tehrani HY, Peterson BG, Katariya K, Morasch MD, Stevens R, DiLuozzo G, et al. Endovascular repair of thoracic aortic tears. Ann Thorac Surg. 2006;82:873-7.
15. Orend KH, Pamler R, Kapfer X, Liewald F, Gorich J, SunderPlassmann L. Endovascular repair of traumatic descending aortic transection. J Endovasc Ther. 2002;9:573-8.

16. Wellons ED, Milner R, Solis M, Levitt A, Rosenthal D. Stent-graft repair of traumatic thoracic aortic disruptions. J Vasc Surg. 2004;40: 1095-100.

17. Rousseau H, Dambrin C, Marcheix B, Richeux L, Mazerolles M, Cron $\mathrm{C}$, et al. Acute traumatic aortic rupture: a comparison of surgical and stent-graft repair. J Thorac Cardiovasc Surg. 2005;129:1050-5.

18. Marcheix B, Dambrin C, Bolduc JP, Arnaud C, Hollington L, Cron C, et al. Endovascular repair of traumatic rupture of the aortic isthmus: midterm results. J Thorac Cardiovasc Surg. 2006;132:1037-41.

19. Kasirajan K, Heffernan D, Langsfeld M. Acute thoracic aortic trauma: a comparison of endoluminal stent grafts with open repair and nonoperative management. Ann Vasc Surg. 2003;17:589-95.

20. Ott MC, Stewart TC, Lawlor DK, Gray DK, Forbes TL. Management of blunt thoracic aortic injuries: endovascular stents versus open repair. J Trauma. 2004;56:565-70.

21. Amabile P, Collart F, Gariboldi V, Rollet G, Bartoli JM, Piquet P. Surgical versus endovascular treatment of traumatic thoracic aortic rupture. J Vasc Surg. 2004;40:873-9. 